Jurnal Penelitian Hasil Hutan

Forest Products Research Journal

Vol. 13, No. 4 (1995) pp. 144 - 152

\title{
PENGARUH PENAMBAHAN UREA DAN MELAMIN PADA PEREKAT UREA FORMALDEHIDA TERHADAP EMISI FORMALDEHIDA DAN KETEGUHAN REKAT TRIPLEKS MERANTI
}

(The effect of urea and melamine addition to urea formaldehyde glue on formaldehyde emission and bonding strength of meranti plywood)

\author{
Oleh/By
}

\section{Paribotro Sutigno \& Adi Santoso}

\section{Summary}

The problem in using plywood bonded with urea formaldehyde (UF) is formaldehyde emission, especially in a room with limited ventilation. To reduce formaldehyde emission, the glue can be mixed with catching agent. In this paper the effect of urea and melamine as catching agent on formaldehyde emission and on bonding strength of UF bonded plywood made from red meranti (Shorea. spp) is discussed.

The effect of catching agent type on formaldehyde emission is not significant while the effect of percentage of catching agent is highly significant on formaldehyde emission. The higher percentage of catching agent, the lower formaldehyde emission of plywood.

The effect of catching agent type on plywood bonding strength is not significant, but the effect of percentage of catching agent is highly significant. The higher percentage of urea the lower plywood bonding strength, while the higher percentage of melamine and urea-melamine cause the higher plywood bonding strength. To meet formaldehyde emission of $0.165 \mathrm{ug} / \mathrm{ml}$, it is recomended to use $10 \%$ urea on the weight basis of liquid UF.

\section{PENDAHULUAN}

Industri kayu lapis di Indonesia berkembang dengan sangat pesat terutama sejak meningkatnya kegiatan Hak Pengusahaan Hutan (HPH) pada dekade 1980-an. Dalam pembuatan kayu lapis yang memegang peranan penting adalah perekatnya karena sifat perekat mempengaruhi daya rekat kayu lapis yang dibuat, walaupun demikian faktor venir tidak boleh diabaikan (Kamil, 1970).

Sebagaimana telah diketahui bahwa kayu lapis yang dibuat di Indonesia sebagian besar menggunakan perekat urea formaldehida (UF), hanya sebagian kecil saja yang menggunakan perekat melamin formaldehida dan fenol formaldehida. Salah satu sifat dari kayu lapis yang dibuat dengan perekat UF adalah terjadinya emisi formaldehida, sehingga dikhawatirkan akan mencemarkan lingkungan berupa gangguan terhadap 
kesehatan bila digunakan dalam ruangan yang relatif tertutup. Berdasarkan hasil penelitian terdahulu, diketahui bahwa emisi formaldehida dari kayu lapis yang dibuat dengan perekat UF dapat dikurangi dengan beberapa macam cara antara lain dengan pemakaian pengeras yang dicampur dengan bahan penangkap (Anonim, 1982) atau dengan mencampurkan pengeras dan penguat dalam perekat UF cair yang dipakai (Sutigno dan Sumadiwangsa, 1985). Penelitian ini bertujuan untuk mengetahui pengaruh penambahan urea dan melamin pada perekat urea formaldehida terhadap emisi formaldehida dan terhadap keteguhan rekat kayu lapis meranti merah. Sasarannya adalah untuk mendapatkan kadar optimum pemakaian kadar bahan penangkap tersebut dimana emisi formaldehidanya dan keteguhan rekat kayu lapisnya memenuhi syarat.

\section{BAHAN DAN METODE}

\section{A. Bahan}

Kayu lapis berupa tripleks dibuat dari venir meranti merah (Shorea.sp), tebal 1,5 $\mathrm{mm}$ dengan perekat urea formaldehida (UF) cair. Perekat ini mempunyai kekentalan 3,2 poise, kadar padat $62 \%$ dan kadar formaldehida bebas $0,12 \%$ dengan uji masa simpan 90 menit dan $\mathrm{pH} 6,5$. Ukuran kayu lapis adalah $40 \mathrm{~cm} \times 40 \mathrm{~cm}$ dengan jumlah perekat yang dilaburkan sebanyak $190 \mathrm{~g} / \mathrm{m}^{2}$ permukaan atau $60,8 \mathrm{~g}$ untuk setiap lembar tripleks.

Secara umum kayu meranti dapat dikelompokkan menjadi meranti merah, meranti kuning dan meranti putih (Martawijaya, Kartasudjana, Kadir dan Prawira, 1981). Semua jenis meranti tersebut di atas dapat dibuat kayu lapis. Bila ditinjau dari sifat emisi formaldehidanya, ada 2 kelompok jenis kayu yaitu jenis kayu yang mudah melepaskan formaldehida seperti meranti merah dan meranti putih serta jenis kayu yang sukar melepaskan formaldehida seperti meranti kuning dan mersawa (Anonim, 1995). Hal ini berarti kayu lapis yang terbuat dari jenis kayu kelompok pertama cenderung untuk mempunyai nilai emisi formaldehida lebih rendah daripada kayu lapis yang terbuat dari jenis kayu kelompok yang kedua. Kecenderungan seperti itu terdapat pula pada papan partikel (Memed, 1987). Sebagai contoh dapat dikemukakan bahwa emisi formaldehida dari papan partikel meranti merah lebih rendah $(11,22$ ppm) daripada papan partikel meranti kuning $(16,72 \mathrm{ppm})$ atau berbeda sekitar $49 \%$.

Bahan penangkap yang dipakai ada 3 macam yaitu urea, melamin dan campuran urea dengan melamin (1:1). Banyaknya bahan penangkap 5\%,10\% dan $15 \%$ dari berat perekat UF cair. Sebagai pengeras digunakan amonium khlorida sebanyak $0,5 \%$ dan terigu sebagai ekstender sebanyak $20 \%$ masing-masing dihitung dari berat UF cair. Penambahan air tidak dilakukan karena kekentalan ramuan perekat berkisar antara $10-13$ poise sesuai dengan anjuran pabrik (Anonim, 1982).

\section{B. Metode}

Bahan kayu lapis dikempa dingin selama 15 menit kemudian dikempa panas selama 5 menit dengan tekanan $12 \mathrm{~kg} / \mathrm{cm}^{2}$ dan suhu $110^{\circ} \mathrm{C}$. Untuk setiap perlakuan dibuat 4 lembar kayu lapis. 
Pengujian emisi formaldehida dilakukan dengan cara desikator selama 2 jam menurut ketentuan standar Amerika (Anonim, 1983) dan menggunakan parafin sebagai media pelapis contoh uji serta spektrofotometer untuk mengukur absorbansinya. Contoh uji sebanyak 8 buah dimasukkan ke dalam desikator setelah dibiarkan dalam ruangan selama seminggu.

Keteguhan rekat kayu lapis diuji menurut standar Indonesia (Anonim, 1985), Jepang (Anonim, 1973) dan Jerman (Anonim, 1975) masing-masing untuk kayu lapis tipe II (interior). Perlakuan terhadap contoh uji menurut standar Indonesia dan standar Jepang adalah perendaman dalam air panas $60{ }^{\circ} \mathrm{C}$ selama 3 jam, pencelupan dalam air dingin sehingga mencapai suhu kamar kemudian diuji selagi masih basah. Sedangkan perlakuan terhadap contoh uji menurut standar Jerman adalah perendaman dalam air panas $670^{\circ} \mathrm{C}$ selama $3 \mathrm{jam}$, kemudian perendaman dalam air dingin selama 2 jam lalu diuji. Data yang dicatat dari ketiga cara uji tersebut adalah beban putus dan kerusakan kayu. Data dari setiap lembar kayu lapis merupakan rataan dari dua buah contoh uji yang masing-masing mempunyai arah retak kupas terbuka dan tertutup.

Percobaan ini memakai rancangan acak tersarang (Sudjana, 1980) dengan faktor macam zat penangkap dan kadarnya. Untuk mengetahui hubungan antara kadar bahan penangkap dengan emisi formaldehida dan dengan keteguhan rekat kayu lapis dilakukan sidik regresi.

\section{HASIL DAN PEMBAHASAN}

\section{A. Ramuan Perekat}

Komposisi perekat dan pengujian beberapa sifatnya tercantum pada Tabel 1. Ada kecenderungan kenaikan kekentalan dengan meningkatnya kadar bahan penangkap karena bahan yang dipakai berupa bahan padat. Sementara itu $\mathrm{pH}$ ramuan perekat berkisar antara 5,2 - 5,4 dan kekentalan 10,0 - 11,2 Poise.

Tabel 1. Komposisi perekat dan sifatnya

Table 1. Glue compositions and their properties

\begin{tabular}{|c|c|c|c|c|c|c|}
\hline \multicolumn{3}{|c|}{$\begin{array}{l}\text { Bahan penangkap } \\
\text { (Catching agent) }\end{array}$} & \multicolumn{4}{|c|}{$\begin{array}{c}\text { Komposisi dan sifat perekat } \\
\text { (Glue compositions and properties) }\end{array}$} \\
\hline Macam (Type) & $\%$ & UF & Eks & Hard & Visc & $\mathrm{pH}$ \\
\hline \multirow{4}{*}{ U } & 5 & 100 & 20 & 0,5 & 10,8 & 5,2 \\
\hline & 10 & 100 & 20 & 0,5 & 10,8 & 5,3 \\
\hline & 15 & 100 & 20 & 0,5 & 10,8 & 5,4 \\
\hline & 5 & 100 & 20 & 0,5 & 10,8 & 5,3 \\
\hline \multirow[t]{3}{*}{ M } & 10 & 100 & 20 & 0,5 & 10,2 & 5,4 \\
\hline & 15 & 100 & 20 & 0,5 & 11,5 & 5,4 \\
\hline & 5 & 100 & 20 & 0,5 & 10,2 & 5,4 \\
\hline \multirow[t]{2}{*}{$\mathrm{UM}$} & 10 & 100 & 20 & 0,5 & 10,5 & 5,4 \\
\hline & 15 & 100 & 20 & 0,5 & 10,8 & 5,4 \\
\hline
\end{tabular}

$\mathrm{U}=$ Urea (Urea), $\mathrm{UF}=$ Urea formaldehida (Urea formaldehyde), $\mathrm{M}=$ Melamin (Melamine)

Eks $=$ Ekstender (Extender), Hard $=$ Pengeras $($ Hardener $)$, Visc $=$ Kekentalan (Viscosity), Poise

$\mathrm{UM}=$ Campuran urea dan melamin (The mixture of urea and melamine) 


\section{B. Emisi Formaldehida}

Ikhtisar hasil penetapan emisi formaldehida tercantum pada Tabel 2. Data tersebut merupakan rataan dari 4 ulangan.

Tabel 2. Emisi formaldehida dari kayu lapis (ug/ml)

Table 2. Formaldehyde emission of plywood (ug/ml)

\begin{tabular}{cccc}
\hline $\begin{array}{c}\text { Macam zat penangkap } \\
(\text { Type of catching agent) }\end{array}$ & \multicolumn{3}{c}{ Kadar zat penangkap (Percentage of catching agent) } \\
\cline { 2 - 4 } & $5 \%$ & $10 \%$ & $15 \%$ \\
\hline U & 0,3463 & 0,0684 & 0,0449 \\
M & 0,0583 & 0,0187 & 0,0124 \\
UM & 0,0357 & 0,0190 & 0,0074 \\
\hline
\end{tabular}

Keterangan (Remarks) :

$\mathrm{U}=$ Urea (Urea)

$\mathrm{M}=$ Melamin (Melamine)

$\mathrm{UM}=$ Campuran (The mixture $U \& M$ )

Persyaratan emisi formaldehida untuk kayu lapis menurut standar Amerika adalah $0,2 \mathrm{ppm}$ berdasarkan cara kamar (Anonim, 1986) atau $0,33 \mathrm{ug} / \mathrm{ml}$ berdasarkan cara desikator. Ada rencana ketentuan tersebut akan diturunkan menjadi $0,1 \mathrm{ppm}$ bahkan $0,025 \mathrm{ppm}$ atau berturut-turut $0,165 \mathrm{ug} / \mathrm{ml}$ dan $0,041 \mathrm{ug} / \mathrm{ml}$ berdasarkan cara desikator. Hasil penelitian yang tercantum pada Tabel 2 menunjukkan bahwa sebagian besar emisi formaldehida dari kayu lapis kurang dari $0,33 \mathrm{ug} / \mathrm{ml}$, sehingga hampir semuanya memenuhi syarat standar Amerika. Demikian pula bila persyaratan ini diturunkan menjadi $0,165 \mathrm{ug} / \mathrm{ml}$, maka hanya satu perlakuan saja yang tidak memenuhi syarat. Tetapi bila persyaratannya diturunkan menjadi $0,041 \mathrm{ug} / \mathrm{ml} \mathrm{maka}$ yang memenuhi syarat adalah yang memakai melamin $10 \%$ dan $15 \%$ serta campuran urea melamin $5 \%, 10 \%$ dan $15 \%$.

Untuk mengetahui pengaruh macam dan kadar zat penangkap terhadap emisi formaldehida dilakukan sidik ragam. Hasilnya tercantum pada Tabel 3 yang menunjukkan bahwa pengaruh macam zat penangkap tidak nyata, sedangkan pengaruh kadarnya sangat nyata.

Tabel 3. Ikhtisar sidik ragam emisi formaldehida

Table 3. Summary of analysis of variance of formaldehyde emission

\begin{tabular}{ccc}
\hline $\begin{array}{c}\text { Sumber keragaman } \\
\text { (Source of variation) }\end{array}$ & $\begin{array}{c}\text {F Fitung }_{\text {hiterangan }} \\
\left(F_{\text {calculated }}\right)\end{array}$ & $\begin{array}{c}\text { Keteran } \\
\text { (Remark) }\end{array}$ \\
\hline $\begin{array}{c}\text { Macam zat penangkap } \\
\text { (Type of catching agent) }\end{array}$ & 1,7047 & \\
$\begin{array}{c}\text { Kadar zat penangkap dalam } \\
\text { macam zat penangkap } \\
\text { (Percentage of catching } \\
\text { agent in type of catching agent) }\end{array}$ & $386^{* *}$ & $\begin{array}{c}\text { Sangat nyata } \\
\text { (Highly significant) }\end{array}$ \\
\hline
\end{tabular}


Oleh karena pengaruh kadar zat penangkap sangat nyata, maka dilakukan uji beda menurut prosedur Tukey (Tabel 4).

Data di atas menunjukkan bahwa terdapat penurunan emisi formaldehida secara sangat nyata sebagai akibat penambahan kadar zat penangkap. Hal ini sejalan dengan penelitian Jung Ihn Hyun et.al (1981) yang menunjukkan adanya penurunan emisi formaldehida sebagai akibat penambahan zat penangkap. Hasil yang serupa di atas diperoleh pula dalam penelitian Sutigno dan Santoso (1990) dalam penelitiannya tentang pengaruh penambahan urea dan amonium karbonat pada perekat urea formaldehida terhadap emisi formaldehida dan keteguhan rekat tripleks jabon.

Karena terjadi penurunan emisi formaldehida dengan bertambah banyaknya kadar zat penangkap maka perlu diketahui hubungan antara kadar zat penangkap dengan emisi formaldehida. Hasil perhitungan sidik regresi tercantum pada Tabel 5 yang menunjukkan bahwa hubungan antara kadar zat penangkap dengan emisi formaldehida bersifat eksponensial hal ini berbeda dengan hasil penelitian sebelumnya dimana hubungan antara kadar zat penangkap dengan emisi formaldehida dinyatakan dengan garis regresi linear (Sutigno dan Santoso, 1990). $\mathrm{Hal}$ ini dimungkinkan karena sifat zat penangkap yang dipakai pada kedua penelitian tersebut berbeda.

Tabel 4. Uji beda emisi formaldehida antar kadar zat penangkap (ug/ml)

Table 4. Test of difference of formaldehyde emission among percentage of catching agent (ug/ml)

\begin{tabular}{cccc}
\hline \multirow{2}{*}{$\begin{array}{c}\text { Jenis zat penangkap, \% } \\
\text { (Type of catching agent), \% }\end{array}$} & \multicolumn{3}{c}{ Kadar zat penangkap (Percentage of catching agent) } \\
\cline { 2 - 4 } & 5 & 10 & 15 \\
\hline U & 0,3463 & 0,0684 & 0,0449 \\
M & 0,0583 & 0,0187 & 0,0124 \\
UM & 0,0357 & 0,0190 & 0,0074 \\
\hline
\end{tabular}

Keterangan (Remark) : : Tidak nyata (Not significant)

Tabel 5. Hubungan antara kadar zat penangkap $(X, \%)$ dengan emisi formaldehida $(\mathbf{Y}, \mathbf{u g} / \mathrm{ml})$

Table 5. Relationship between percentage of catching agent $(\mathrm{X}, \%)$ and formaldehyde emission (Y, ug/ml)

\begin{tabular}{ccccc}
\hline $\begin{array}{c}\text { Macam zat penangkap } \\
\text { (Type of catching agent) }\end{array}$ & $\begin{array}{c}\text { Hubungan } \\
\text { (Relationship) }\end{array}$ & $\begin{array}{l}\text { F } \\
\left(\mathrm{F}_{\text {calc }}\right)\end{array}$ & $\mathrm{n}$ & $\mathrm{r}$ \\
\hline $\mathrm{U}$ & $\mathrm{Y}=8,0131 \mathrm{X}^{-1,9686}$ & $250,64^{* *}$ & 12 & $-0,9807$ \\
$\mathrm{M}$ & $\mathrm{Y}=0,6094 \mathrm{X}^{-1,4941}$ & $84,27^{* *}$ & 12 & $-0,8946$ \\
$\mathrm{UM}$ & $\mathrm{Y}=0,3643 \mathrm{X}^{-1,3896}$ & $40,14^{* *}$ & 12 & $-0,9455$
\end{tabular}

Keterangan (Remark) : ${ }^{* *}$ Sangat nyata (Highly significant) 


\section{Keteguhan Rekat Kayu Lapis}

Pada Tabel 6 tercantum ikhtisar hasil pengujian keteguhan rekat kayu lapis berdasarkan standar Indonesia, standar Jepang dan standar Jerman. Data ini masingmasing merupakan rataan dari 4 ulangan.

Tabel 6. Keteguhan rekat kayu lapis dinyatakan dalam beban putus dalam $\mathrm{kg} / \mathrm{cm}^{2}$ (1) dan kerusakan kayu dalam \% (2 \& 3)

Table 6. Plywood bonding strength as indicated by failing load in $\mathrm{kg} / \mathrm{cm}^{2}(1)$ and wood failure in $\%(2 \& 3)$

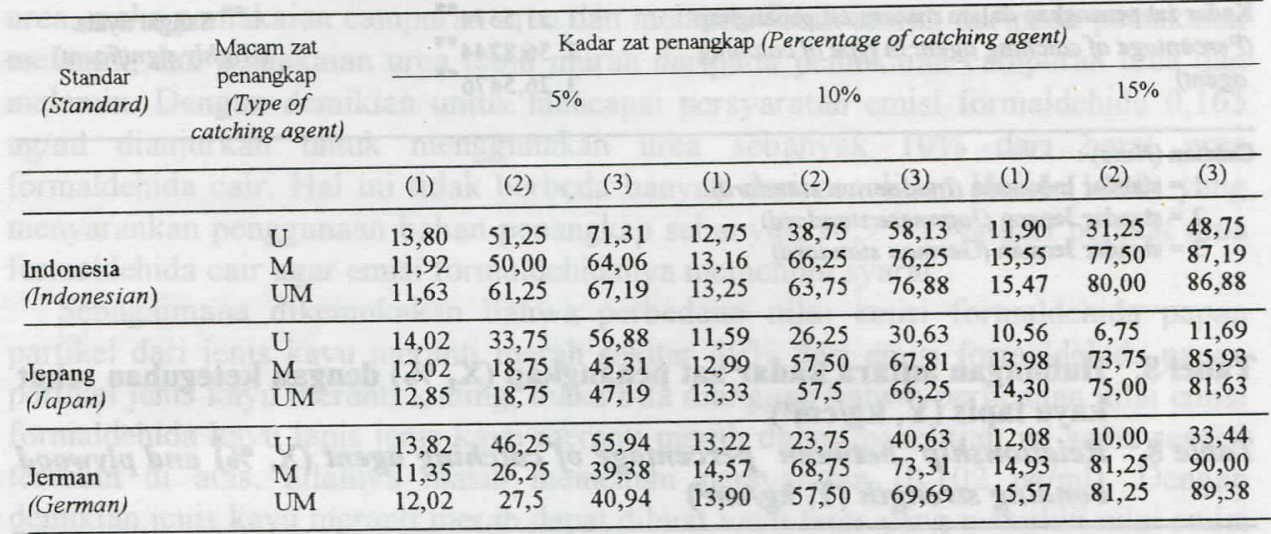

Keterangan (Remarks):

$\mathrm{U}=$ Urea (Urea)

$\mathrm{M}=$ Melamin (Melamine)

$\mathrm{UM}=$ Campuran urea dan melamin (The mixture of urea and melamine).

(2) $=\%$ minimum kerusakan kayu (minimum $\%$ of wood failure).

(3) $\%$ rataan kerusakan kayu (average $\%$ of wood failure).

Hasil pengujian kayu lapis untuk semua perlakuan ternyata sebagian besar memenuhi persyaratan standar Indonesia karena nilai keteguhan rekatnya kurang dari $17,6 \mathrm{~kg} / \mathrm{cm}^{2}$ dengan kerusakan kayu minimum lebih dari $25 \%$ dan rata-ratanya tidak kurang dari $50 \%$. Menurut standar Jepang keteguhan rekat minimum untuk kayu lapis adalah $7 \mathrm{~kg} / \mathrm{cm}^{2}$, dengan demikian semua perlakuan yang dikenakan pada kayu lapis dalam percobaan ini memenuhi syarat karena keteguhan rekatnya tidak ada yang kurang dari $7 \mathrm{~kg} / \mathrm{cm}^{2}$. Hasil pengujian keteguhan rekat menurut standar Jerman yang dilakukan pada kayu lapis tersebut juga menunjukkan data yang seluruhnya memenuhi persyaratan standar Jerman untuk tipe II oleh karena keteguhan rekatnya lebih dari $10 \mathrm{~kg} / \mathrm{cm}^{2}$.

Selanjutnya untuk mengetahui pengaruh macam zat penangkap dan kadarnya terhadap keteguhan rekat kayu lapis dilakukan perhitungan sidik ragam (Tabel 7). Data yang diolah adalah nilai beban putus.

Macam zat penangkap tidak berpengaruh nyata sedangkan kadar zat penangkap berpengaruh sangat nyata terhadap keteguhan rekat kayu lapis. Untuk mengetahui hubungan antara kadar zat penangkap dengan keteguhan rekat kayu lapis dilakukan sidik regresi (Tabel 8). Ternyata hubungan tersebut dapat dinyatakan dengan garis regresi linier.

For. Prod. Res. J. Vol. 13 No. 4 (1995) 
Tabel 7. Ikhtisar sidik ragam keteguhan rekat kayu lapis

Table 7. Summary of analysis of variance of plywood bonding strength.

\begin{tabular}{llc}
\hline \multicolumn{1}{c}{$\begin{array}{c}\text { Sumber keragaman } \\
\text { (Source of variation) }\end{array}$} & $\begin{array}{c}F_{\text {hitung }} \\
\left(F_{\text {calculated }}\right.\end{array}$ & $\begin{array}{c}\text { Keterangan } \\
\text { (Remark) }\end{array}$ \\
\hline Macam zat penangkap & $1.0,1738$ \\
(Type of catching agent) & $2.0,5857$ \\
& $3.0,1990$ & ** Sangat nyata \\
Kadar zat penangkap dalam macam zat penangkap & $1.31,5574^{* *}$ & (Highly significant) \\
Percentage of catching agent in type of catching & $2.56,8244^{* *}$ &
\end{tabular}

Catatan (Note) :

1 = standar Indonesia (Indonesian standard)

2 = standar Jepang (Japanese standard)

3 = standar Jerman (German standard)

Tabel 8. Hubungan antara kadar zat penangkap $(X, \%)$ dengan keteguhan rekat kayu lapis $\left(\mathrm{Y}, \mathrm{kg} / \mathrm{cm}^{2}\right)$

Table 8. Relationship between percentage of catching agent $(X, \%)$ and plywood bonding strength $\left(Y, \mathrm{~kg} / \mathrm{cm}^{2}\right)$

\begin{tabular}{lcccc}
\hline $\begin{array}{c}\text { Standar } \\
\text { Standard) }\end{array}$ & $\begin{array}{c}\text { Macam zat penangkap } \\
\text { (Type of catching agent) }\end{array}$ & $\begin{array}{c}\text { Hubungan } \\
\text { (Relationship) }\end{array}$ & $\begin{array}{c}\text { F }_{\text {hitung }} \\
\text { (F calculated }\end{array}$ & $\mathrm{r}$ \\
\hline Indonesia & $\mathrm{U}$ & $\mathrm{Y}=14,72-0,19 \mathrm{X}$ & $15,93^{* *}$ & $-0,87$ \\
(Indonesian) & $\mathrm{M}$ & $\mathrm{Y}=9,74+0,36 \mathrm{X}$ & $58,23^{* *}$ & 0,86 \\
& $\mathrm{UM}$ & $\mathrm{Y}=9,63+0,38 \mathrm{X}$ & $65,26^{* *}$ & 0,93 \\
\hline Jepang & $\mathrm{U}$ & $\mathrm{Y}=15,83-0,37 \mathrm{X}$ & $155,20^{* *}$ & $-0,94$ \\
(Japan) & $\mathrm{M}$ & $\mathrm{Y}=11,03+0,20 \mathrm{X}$ & $43,71^{* *}$ & 0,95 \\
& $\mathrm{UM}$ & $\mathrm{Y}=11,27+0,20 \mathrm{X}$ & $46,56^{* *}$ & 0,94 \\
\hline Jerman & $\mathrm{U}$ & $\mathrm{Y}=14,78-0,17 \mathrm{X}$ & $9,80^{* *}$ & $-0,89$ \\
(German) & $\mathrm{M}$ & $\mathrm{Y}=9,54+0,43 \mathrm{X}$ & $60,45^{* *}$ & 0,85 \\
& $\mathrm{UM}$ & $\mathrm{Y}=10,04+0,37 \mathrm{X}$ & $14,92^{* *}$ & 0,96 \\
\hline
\end{tabular}

Keterangan (Remarks) : ** Sangat nyata (Highly significant)

Keteguhan rekat kayu lapis sangat dipengaruhi oleh kadar zat penangkap urea, melamin dan campuran urea-melamin yang ditambahkan ke dalam perekat. Dengan bertambahnya kadar melamin dan campuran urea melamin maka keteguhan rekat kayu lapis cenderung semakin tinggi, sedangkan penambahan zat penangkap urea yang semakin banyak ke dalam perekat cenderung menurunkan keteguhan rekat kayu lapis. Hal ini serupa dengan hasil penelitian terdahulu dimana penambahan zat penangkap berupa urea cenderung menurunkan keteguhan rekat kayu lapis jabon (Sutigno dan Santoso, 1990).

Bila berpedoman pada persyaratan emisi formaldehida $0,165 \mathrm{ug} / \mathrm{ml}$ maka penggunaan zat penangkap berupa urea sebanyak $10 \%-15 \%$ dan melamin serta campuran urea-melamin sebanyak 5\% - 15\% semuanya memenuhi syarat (Tabel 2), 
demikian pula dengan keteguhan rekat kayu lapisnya sebagian besar memenuhi persyaratan standar Indonesia, Jepang dan Jerman (Tabel 6) karena beban putusnya masih dalam batas yang diperkenankan menurut masing-masing standar tersebut. Dibandingkan dengan urea, pemakaian melamin lebih baik daripada urea karena untuk penggunaan dengan kadar yang sama $(5 \%)$ emisi formaldehida kayu lapisnya jauh lebih rendah daripada persyaratan IHPA, dan bila penggunaannya ditingkatkan menjadi $10 \%-15 \%$, maka selain emisi formaldehida kayu lapis semakin rendah, keteguhan rekat kayu lapisnyapun semakin meningkat. Walaupun demikian, perlu diperhatikan pertimbangan ekonominya. Karena harga melamin lebih mahal daripada urea, maka pemakaian campuran urea dan melamin lebih murah daripada pemakaian melamin, dan pemakaian urea lebih murah daripada pemakaian campuran urea dan melamin. Dengan demikian untuk mencapai persyaratan emisi formaldehida 0,165 $\mathrm{ug} / \mathrm{ml}$ dianjurkan untuk menggunakan urea sebanyak $10 \%$ dari berat urea formaldehida cair. Hal ini tidak berbeda banyak dari penelitian Halid (1995) yang menyarankan penggunaan bahan penangkap sebanyak $10,9-13 \%$ dari perekat urea formaldehida cair agar emisi formaldehidanya memenuhi syarat.

Sebagaimana dikemukakan bahwa perbedaan nilai emisi formaldehida papan partikel dari jenis kayu meranti merah sekitar $49 \%$ dari emisi formaldehida papan partikel jenis kayu meranti kuning, maka bila dianggap bahwa perbedaan nilai emisi formaldehida kayu lapis jenis kayu meranti merah dalam penelitian ini sama seperti tersebut di atas, nilainya masih memenuhi persyaratan $(0,102 \mathrm{ug} / \mathrm{ml})$. Dengan demikian jenis kayu meranti merah dapat dibuat kayu lapis yang memiliki nilai emisi formaldehida rendah dengan perekat urea formaldehida dan bahan penangkap berupa urea sebanyak $10 \%$ dari berat perekat cair.

\section{KESIMPULAN DAN SARAN}

Emisi formaldehida kayu lapis sangat dipengaruhi oleh kadar zat penangkap dalam perekat. Semakin tinggi kadar zat penangkap, makin rendah emisi formaldehida kayu lapis. Pengaruh macam zat penangkap terhadap emisi formaldehida tidak nyata. Hubungan antara kadar zat penangkap dengan emisi formaldehida dapat dinyatakan secara eksponensial.

Macam zat penangkap tidak mempengaruhi keteguhan rekat kayu lapis secara nyata, sedang kadar zat penangkap berpengaruh sangat nyata terhadap keteguhan rekat kayu lapis. Makin tinggi kadar zat penangkap berupa urea, makin rendah keteguhan rekat kayu lapis, sedang makin tinggi kadar zat penangkap berupa melamin dan campuran urea-melamin maka keteguhan rekat kayu lapisnya cenderung makin meningkat pula. Hubungan antara kadar zat penangkap dengan keteguhan rekat kayu lapis dapat dinyatakan dengan garis regresi linier. Keteguhan rekat kayu lapis tertinggi terdapat pada pemakaian melamin sedangkan yang terendah terdapat pada pemakaian urea. Pemakaian campuran urea-melamin menghasilkan keteguhan rekat kayu lapis di antara keduanya.

Untuk mencapai emisi formaldehida $0,165 \mathrm{ug} / \mathrm{ml}$ disarankan untuk dapat memakai urea sebanyak $10 \%$ dari berat urea formaldehida cair. Keteguhan rekat kayu lapisnya masih memenuhi persyaratan standar Indonesia, Jepang dan Jerman. 


\section{DAFTAR PUSTAKA}

Anonim. 1973. Japanese Agricultural Standard of common plywood and its commentary. The Japan Plywood Inspection Corporation. The Japan Plywood Manufacturers Association, Tokyo. pp.60 - 73.

1975. DIN Taschenbuch 60. Beuth Verlag Cmbh, Berlin, Koln, Frankfurt (Main). pp.49 - 51.

1981a. Mutu dan cara uji kayu lapis. Standar Industri Indonesia (SII) 04041980. Departemen Perindustrian. Jakarta.

- 1981b. Tentative test method for emission of formaldehyde from wood products. Desicator method. Imported Hardwood Products Association, Inc. Washington D.C pp. 1-7.

1982. Data teknik urea formaldehida resin adhesive. PT. Palmolite Adhesive Industry, Probolinggo. 4pp.

- 1983. Small scale test method for determining formaldehyde emission from wood products, two hour desicator test. FTMI-1983. National Particleboard Association Maryland. Hardwood Plywood Manufacturers Association, Virginia, Formaldehyde Institute, New York.

1986. Purchase specifications for 3 ply wall panel imported hardwood plywood from Southeast Asia. International Hardwood Products Association, Alexandria. p. 4.

1995. Teknik Produksi Kayu Lapis Rendah Emisi Formaldehida. Lokakarya Sistem Mutu dan Sistem Produksi F.2. Jakarta.

Halid, M. 1995. Sistem Perekatan Pada Proses Pembuatan Produk Kayu Lapis F.2. PT. Lakosta Indah, Samarinda.

Jung Ihn Hyun, Yeon Heung Chung, Yong Dae Lee and Jae Myeong Jo. 1981 Eliminating odor of formaldehyde emission from urea-formaldehyde adhesive plywood. The Research Reports No. 28. Forest Research Institute, Seoul. pp. $89-110$.

Kamil, R. N. 1970. Kayu Agatis (Agathis spec) sebagai bahan kayu lapis. Pengumuman No. 96. Lembar Penelitian Hasil Hutan, Bogor. hal. 38 - 41.

Martawijaya A, I. Kartasudjana, K. Kadir dan S.A. Prawira. 1981. Atlas Kayu Indonesia. Balai Penelitian Hasil Hutan. Bogor.

Sudjana. 1980. Disain dan analisis eksperimen. Tarsito, Bandung. hal. 200 - 206, 225.

Sutigno, P. dan S. Sumadiwangsa. 1985. Pengaruh komposisi perekat terhadap emisi formaldehida dan keteguhan rekat kayu lapis. Jurnal Penelitian Hasil Hutan 2(2): $20-25$.

Sutigno, P. dan A. Santoso. 1990. Pengaruh urea dan amonium karbonat pada perekat urea formaldehida terhadap emisi formaldehida dan keteguhan rekat tripleks jabon. Jurnal Penelitian Hasil Hutan 7(1): 12-16. 